To cite this article:

Ann Torugsa Kritcha Yawised and Wayne O'Donohue, (2013) "Use Web 2.0 tools for employeedriven innovation", Strategic HR Review, Vol. 12 Iss: 3.

\title{
Use Web 2.0 tools for employee-driven innovation
}

\section{Practical advice for HR professionals}

In today's digital-focused environment, knowledge as the critical business asset is converging with Web 2.0 (online applications or social media), where employees can share their knowledge in new collaborative ways via peer-to-peer networks, blogs, wikis, podcasts and other forms of usergenerated content. However, while the open and democratic nature of Web 2.0 can trigger employee-driven innovation (EDI) - a bottom-up innovative process driven by ideas, experience, creativity and skills of the firm's employees (Høyrup, 2010) - it can also present significant challenges in the art of managing employees.

Innovation cannot be encouraged simply by making Web 2.0 available in the workplace. As a mechanism through which employee empowerment can be operationalized, Web 2.0 offers HR managers a new channel for listening to the employee's voice, and a means of maximizing learning and knowledge sharing within their organizations. Following are the five "Ds" by which HR managers can get the best out of their Web 2.0 efforts.

Decide carefully

The value of Web 2.0 as a knowledge-sharing tool can vary between organizations. Key factors determining value include the nature of social interaction in an organization, the level of reliance on creativity and innovativeness to solve problems, and the extent to which there is a collaborative culture between employees for capitalizing on new opportunities. Other shaping factors include organizational hierarchy and culture, as well as the sensitivity of customer data and threats to information.

For example, advertising, design and software companies will have much to gain and little to lose from boosting EDI via Web 2.0, given they are often characterized by employees with an abundance of creative energy and value-creation opportunities in knowledge-sharing and collaboration. On the other hand, financial institutions such as banks are much more constrained by hierarchy and data security, and often encourage competition among employees for limited promotion opportunities. Under such conditions, Web 2.0 may be less effective for generating EDI.

Understanding the social nature of the organization and deciding carefully whether and which Web 2.0 applications should be used are therefore the first steps towards the successful integration of Web 2.0 into an organization's innovation processes.

\section{Define collective objectives}

Defining clear objectives for Web 2.0 usage, which embody the collective aspirations of employees and encourage organizational learning and creativity, is essential for promoting effective knowledgesharing. For example, framing objectives that clarify the scope and purpose of collaboration, as well as who will be involved, why, and at what point in time, will send a strong signal to employees that the organization supports EDI. When all organizational members share the same perceptions about the purpose of using Web 2.0 as a knowledge-sharing tool, possible misunderstanding in online communications can be avoided, and more opportunities to exchange innovative ideas and work collaboratively can be created. At the same time, all staff need to understand that Web 2.0 is just a 
tool to make it easier to work together, and the main internal communications route remains faceto-face.

\section{Develop a collaborative environment}

Interactive collaboration for EDI should be voluntary as it cannot be generated in a command-andcontrol environment. To achieve such an outcome, HR managers need to develop a positive collaborative environment that fosters workplace learning and knowledge creation. This process can be initiated by creating topic discussion starters that employees would find interesting and valuable, posting them on an internal wiki with blogging and comments functions, and using some form of rewards or incentives to motivate employees to become involved. All employee contributions and ideas should be given proper consideration in order to avoid employees feeling that the use of Web 2.0 tools to share and come up with innovative ideas is a "waste of time" as their ideas will not be taken seriously. A set up of cross-functional EDI teams can also systematically reinforce the connection between organizational actions of promoting knowledge-sharing via Web 2.0 and employee values.

\section{Drop undesirable contributions}

Notwithstanding the need to treat employee contributions seriously, appropriate action must be taken to exclude "undesirable" contributions and modes of participation brought about by the misuse of Web 2.0 tools by employees. Unless such precautions are taken a decline in productivity may ensue as employees become distracted. Ideally, HR managers may call for employee volunteers to act as "ambassadors" to challenge or deal with inappropriate employee contributions and behaviour. Actions however must be taken in a manner that does not destroy the self-directed flow of creative ideas or the ethos of collaboration, or become interpreted as interference by the management.

\section{Drive proactively}

To drive and enhance the knowledge-sharing value of Web 2.0, proactively managing and monitoring interactive collaboration is vital. Topics for collaboration need to be immediate and exciting. On-going feedback should be provided by management in response to staff comments via the wiki or blog. This will assist in openness of communication and encourage employees to engage in EDI on an on-going basis. Being flexible and aware of the changes that will result from new emerging technologies will also enable an organization to capitalize on new knowledge-sharing tools for EDI.

\section{References}

Høyrup, S. (2010), "Employee-driven innovation and workplace learning: basic concepts, approaches and themes", Transfer: European Review of Labor and Research, Vol. 16 No. 2, pp. 143-154

\section{About the authors}

Dr Ann Torugsa is a research fellow at the Australian Innovation Research Centre, University of Tasmania, Australia. Her research interests include technological and non-technological innovations, knowledge transfer, corporate social responsibility and strategic human resource management. She has co-authored a number of academic articles and book chapters. Ann Torugsa is the corresponding author and can be contacted at: Nuttaneeya.Torugsa@utas.edu.au

Kritcha Yawised is a doctoral candidate at the School of Computing and Information Systems, University of Tasmania. His research interests include Web 2.0 tools, and social customer 
relationship management. Yawised previously worked as an IT technical support specialist at Hydro Tasmania, Australia's leading renewable energy company.

Dr Wayne O'Donohue is a lecturer in the Griffith Business School, Griffith University. His primary teaching and research interests are in the fields of organizational behavior and HR management. Prior to commencing an academic career, Dr O'Donohue was for many years a senior HR manager with the Commonwealth Scientific and Industrial Research Organization (CSIRO), Australia's premier scientific research institute. 